\title{
"Positive leadership and organizational identification: Mediating roles of positive emotion and compassion"
}

\begin{tabular}{|c|c|c|}
\hline AUTHORS & $\begin{array}{l}\text { Sung-Hoon Ko } \\
\text { Yongjun Choi }\end{array}$ & \\
\hline ARTICLE INFO & $\begin{array}{l}\text { Sung-Hoon Ko and Yongjun Ch } \\
\text { identification: Mediating roles of } \\
\text { Perspectives in Management, } 1\end{array}$ & $\begin{array}{l}\text { leadership and organizational } \\
\text { nd compassion. Problems and } \\
21511 / \text { ppm.19(1).2021.02 }\end{array}$ \\
\hline DOI & http://dx.doi.org/10.21511/ppm.1 & \\
\hline RELEASED ON & Monday, 18 January 2021 & \\
\hline RECEIVED ON & Thursday, 14 May 2020 & \\
\hline ACCEPTED ON & Monday, 11 January 2021 & \\
\hline LICENSE & $\begin{array}{l}(c) E Y \\
\text { This work is licensed under a C } \\
\text { License }\end{array}$ & Attribution 4.0 International \\
\hline JOURNAL & "Problems and Perspectives in 1 & \\
\hline ISSN PRINT & $1727-7051$ & \\
\hline ISSN ONLINE & $1810-5467$ & \\
\hline PUBLISHER & LLC "Consulting Publishing Cor & erspectives" \\
\hline FOUNDER & LLC "Consulting Publishing Cor & "erspectives" \\
\hline$\sigma^{0}$ & $B$ & $\begin{array}{l}\text { ニこ: } \\
\text { 三こ: }\end{array}$ \\
\hline NUMBER OF REFERENCES & NUMBER OF FIGURES & NUMBER OF TABLES \\
\hline 45 & 0 & 5 \\
\hline
\end{tabular}

(c) The author(s) 2021. This publication is an open access article. 


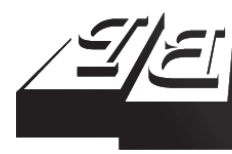

\section{BUSINESS PERSPECTIVES}

LLC "CPC "Business Perspectives" Hryhorii Skovoroda lane, 10, Sumy, 40022, Ukraine www.businessperspectives.org
Received on: $14^{\text {th }}$ of May, 2020 Accepted on: $11^{\text {th }}$ of January, 2021 Published on: $18^{\text {th }}$ of January, 2021

(c) Sung-Hoon Ko, Yongjun Choi, 2021

Sung-Hoon Ko, Ph.D., Assistant Professor, Graduate School of Education, Kyonggi University, Suwon, South Korea.

Yongjun Choi, Ph.D., Assistant Professor, College of Business Administration, Hongik University, Seoul, South Korea. (Corresponding author)
POSITIVE LEADERSHIP AND ORGANIZATIONAL IDENTIFICATION: MEDIATING ROLES OF POSITIVE EMOTION AND COMPASSION

\begin{abstract}
This study examined the effect of positive leadership experienced by employees on their organizational identification and the mechanisms through how positive leadership enhances organizational identification. Despite the importance of positive leadership at work, such as increasing the followers' positive self-concepts at work, our understanding of the mechanisms through how positive leadership leads to employees' organizational identification is still in a nascent state. Thus, this study addresses the research gap by investigating the mediating roles of compassion and positive emotions in the relationship between positive leadership and organizational identification. This study used path analysis and bootstrapping to analyze the survey data collected from 312 full-time employees in 10 large-sized companies located in South Korea. The path analysis results confirmed that positive leadership increases employees' organizational identification. Furthermore, positive leadership enhances compassion and positive emotions at work, which, in turn, leads to higher organizational identification. Most importantly, the bootstrapping results revealed that both compassion and positive emotion mediate the positive relationship between positive leadership and organizational identification. The empirical results broaden the understanding of the mechanisms through how positive leadership could bring positive effects at work, such as employee organizational identification. Thus, from the managerial perspective, organizations could emphasize the importance of positive leadership at work, and provide the managers with opportunities to develop their positive leadership.
\end{abstract}

\section{Keywords}

positive organizational scholarship, positive leadership, work stress, compassionate behaviors, high-quality connections, affective mechanism

JEL Classification

D23, M12

\section{INTRODUCTION}

Employees interact with a wide range of organizational insiders. Among the insiders, leaders' behaviors (i.e., leadership) play important roles in shaping employees' (i.e., followers') work behaviors and attitudes (D'Innocenzo et al., 2016; Hoch et al., 2018; Montano et al., 2017). Leadership scholars have recently started paying their attention to positive leadership, emphasizing the leaders' positive behaviors, encouraging employees' positive work experiences, and even enhancing their competencies and performance (Youssef-Morgan \& Luthans, 2013). Besides, after the 09.11 terrorist attacks in 2001, positive organizational scholarship, based on positive psychology, has received increasing attention in the management and psychology literature. Since then, scholars have developed and started exploring the effects of positive organizational constructs, such as positive leadership, compassion, and positive emotion. Regarding positive leadership, YoussefMorgan and Luthans (2013), in their qualitative research, discussed its meaning and application across different cultures. Furthermore, in their qualitative research, Cameron and Plews (2012) investigated how 
positive leadership behaviors can be applied through the positive organizational scholarship lens within work environments, family, and personal lives. However, empirical results of the relationships between positive leadership and other positive organizational constructs and the mechanisms through how positive leadership leads to desirable outcomes at work are still limited. Hence, this study attempts to investigate the positive effects of positive leadership on employees' organizational identification. Besides, to enhance the knowledge about the mechanisms through how positive leadership enhances employees' organizational identification, this study aims at exploring the mediating roles of compassion and positive emotions in the relationship between positive leadership and organizational identification.

This study provides positive leadership literature with theoretical implications. Firstly, by exploring the positive effects of positive leadership on organizational identification, this study extends the knowledge on positive leadership. It emphasizes its importance, especially for leaders dealing with employees under a great deal of work stress, exhaustion, and burnout in the organizations. Besides, by examining the mechanisms through how positive leadership energizes organizational identification, this study provides fruitful ways to further investigate the effects of positive leadership at work. This study also provides practical implications to the organizations by highlighting positive leadership in organizations. Specifically, when employees experience high levels of stress at work, positive leadership behaviors can facilitate the quality relationships with leaders (e.g., development of gratitude, forgiveness, consideration, and care) and development of positive emotion at work, which helps them perceive high levels of organizational identification.

\section{LITERATURE REVIEW AND HYPOTHESES DEVELOPMENT}

\subsection{Positive leadership and positive emotion}

Cameron (2012) focused on human virtues and happiness, and defined positive leadership as leadership that induces positive emotion among members of an organization, promotes positive attitudes, and ultimately leads to the highest performance. Unlike the most previous leadership theories, which do not fully capture leader positivity, positive leadership emphasizes leader positivity, such as high levels of leaders' psychological capital, increasing employees' positive experience at work (Kelloway et al., 2013). Specifically, positive leadership elicits employees' positive responses, such as enhanced positive self-concepts, because it enables employees to experience positive work events (Hannah et al., 2009). Supporting this, Youssef-Morgan and Luthans (2013) found that positive leadership encourages an organizational spirit among its members, fosters resilience, and enables them to develop their competencies by focusing on their strengths.
Affective event theory (Weiss \& Cropanzano, 1996) suggests that the experiences of work events trigger employees' affective reactions, which, in turn, emotion their work attitudes and behaviors. According to this theory, it is likely that employees who experience positive leadership behaviors interpret the interactions with their leaders positively, leading to their positive emotions. It is consistent with Cameron (2012) and Lilius et al. (2008) arguing the positive relationships between positive leadership and employee's positive emotions. It is also congruent with Kelloway et al. (2013), emphasizing the roles of positive leadership behaviors in leading to employees' positive emotions. Thus, based on the affective events theory and previous literature, the following hypothesis has been established.

\section{H1: Positive leadership is positively related to positive emotion.}

\subsection{Positive leadership and compassion}

Regarding the roles of compassion in organizations, since Lilius et al. (2008) have developed the measurement items for compassion at work, previous studies demonstrated the causal relationships between positive organizational constructs and compassion (e.g., Ko \& Choi, 2019; Lilius et al., 2008). For example, 
Moon et al. (2014) demonstrated the causal relationships between corporate social responsibility (CSR), compassion, organizational justice, and affective commitment. In a recent study, Hur et al. (2018) also demonstrated the causal relationships between CSR, compassion, and creativity. However, the roles of compassion in explaining the effects of positive leadership have received relatively little attention in the field. It is also true for the roles of employee emotion. Although leadership can trigger employees' affective reactions (Damen et al., 2008; Rego et al., 2014), employee emotion has received scant attention in the previous literature on positive leadership.

Positive leadership, rooted in positive psychology, focuses on leaders' behaviors in improving the quality of life among healthy people. Specifically, it was derived from the positive organizational scholarship and emphasized the positive aspects of individuals and the relationships among individuals, groups, and the organization. Cameron (2008) states that positive leadership consists of positive moods, positive relationships, positive communication, and positive meanings. It creates a positive atmosphere within an organization where positive emotion means a stronger work environment or organizational culture.

Employees can create a positive organizational culture by being considerate, forgiving, and expressing gratitude toward one another through the act of compassionate care. Positive leadership can likely facilitate employees' compassionate behaviors because it leads to a high-quality connection beyond simply being close to one another or having a one-time relationship among the employees (Kahn, 1993). Positive leadership can serve as the driving force for employees to spread narratives about care and forgiveness, thanksgiving, and compassion within organizations, and create a compassionate climate at the organizational level (Miller, 2007).

Social exchange theory (Blau, 1964) also supports the above prediction. It provides a conceptual basis for understanding the relationship between individuals and organizations and the formation and development of interactions between individuals (Eisenberger et al., 1997). Social exchange argues that if an individual receives a positive response from another, such as appreciation and trust, he or she must give back. As such, the social exchange theory em- phasizes the inner psychological exchange between human beings or between organizations and workers. Thus, when employees experience positive leadership from their leaders, they develop feelings of gratitude and trust, and the feeling of appreciation and trust is, in turn, passed on to other employees through compassion.

\section{H2: Positive leadership is positively related to compassion.}

\subsection{Positive emotion and organizational identification}

The positive effects of positive emotion at work are well established in the literature. For example, Staw and Barsade (1993) found that employees who experienced more positive emotions are more active in their organizations compared to those who did not. A study by Brief and Roberson (1989) also found that the positive emotion experienced by employees over the previous few weeks had a significant impact on overall performance variables, and Fisher (2000) found that positive and negative emotions play an important role as the leading variables of performance variables. In a similar vein, Lilius et al. (2008) have found empirical evidence that positive emotion has a significant positive effect on performance variables.

It is predicted that employees who experience positive emotions at work are likely to perceive high organizational identification levels. Organizational identification refers to the "perception of oneness with or belongingness to [the organization]" (Ashforth \& Mael, 1989, p. 34). In other words, it captures the extent to which employees perceive the congruence of their own and their organizational values. When employees experience positive emotions at work, they are likely to form positive attitudes toward the organizations, leading to emotional attachment to and identification with the organization (Meyer \& Allen, 1991). Supporting this, Fredrickson (2001) argues that employees' positive affective responses lead to positive outcomes, such as organizational identification and emotional attachment, and reduce dysfunction, such as negative attitudes toward the organization.

H3: Positive emotion is positively related to organizational identification. 


\subsection{Compassion and organizational identification}

When employees experience compassion in an organization, they develop a greater emotional attachment to the organization (Meyer \& Allen, 1991). According to the affective event theory (Weiss \& Cropanzano, 1996), the experience of compassion is likely to be perceived as positive events within an organization. Specifically, employees who experience compassionate acts by others are likely to perceive they are genuinely cared for by their organizations. As a result, employees are likely to perceive their organizations as good places to work with and have a sense of pride toward their organization (Cialdini et al., 1976). Thus, based on the social identity theory (Tajfel \& Turner, 1986), employees are more likely to be attached to their organizations (Rhoades et al., 2001), which, in turn, identify themselves with the organizations. Especially, because compassionate acts within an organization often arise in response to employees struggling with their tasks, the experience of compassion could assist in balancing their lives and tasks and reduce conflict and further strengthen organizational identification (Allen, 2001).

Dutton and his colleagues argued that identifying with an organization is determined by two organization images (Dutton \& Dukerich, 1991; Dutton et al., 1994). First is the organization's identity as recognized by members of the organization. This is the belief in how different a particular organization is from other organizations and how long the differentiated image can last. Second, organizational identification is the belief of members of an organization about how people outside the organization perceive the organization. Dutton et al. (1994) stated that these two beliefs determine how attractive an organization is to its members. They also argued that an organization's attractiveness determines how its members identify with it (Dutton et al., 1994). Members who experience positive leadership within the organization will experience compassion through the caring behavior of the leader who responds to suffering and will develop an organizational identification in the sense that an organization with a compassionate organizational culture is different from other organizations. Besides, members of the organization who have experienced compassion through posi- tive leadership develop an organizational identification from the perspective that external members will have a good image of their organization. Therefore, based on the social identity theory, positive leadership induces compassion within an organization, and eventually, it becomes the driving force for improving organizational identification.

H4: Compassion is positively related to organizational identification.

\subsection{Mediation effects of positive emotion and compassion in the relationship between positive leadership and organizational identification}

Positive leadership inspires employees to focus on their strengths to facilitate the development of their competencies and potential (Youssef-Morgan \& Luthans, 2013; Linley et al., 2007). Compared to traditional leadership trait theories, it is unique in that it explains the characteristics or context of followers (Kirkpatick \& Locke, 1991; Youssef \& Luthans, 2012) as well as the mechanisms by which the employees develop their competencies to produce the highest possible outcomes (Youssef \& Luthans, 2012).

Leadership behaviors are important in forming and developing the relationships between a leader and subordinates. According to the leader-member exchange theory (LMX), employees receiving limited feedback and support from their leader are likely to perceive themselves as out-groups, which, in turn, can raise the issues of unfairness among employees (Liden et al., 2006). However, the target of positive leadership behaviors is all the subordinates' behavior and performance of all the employees (Youssef \& Luthans, 2012). Therefore, employees who experience positive leadership are likely to have positive attitudes toward their leaders and organizations hoping that their capabilities and potential can be developed (Youssef-Morgan \& Luthans, 2013). Besides, based on the social identity theory (Tajfel \& Truner, 1986), employees are likely to identify themselves with the organization. They have the passion and attachment to achieve the organization's common goals with their colleagues, subordinates, and supervisors (Ashforth \& Mael, 1989). Furthermore, positive leadership experience allows 
healthy and productive interactions with others facilitating employees' sense of pride of belonging to their organizations (Bartel, 2001).

\section{H5: Positive leadership is positively related to or- ganizational identification.}

Based on the prior hypotheses, it is predicted that positive emotion and compassion mediate the relationship between positive leadership and organizational identification. First, following the affective events theory (Weiss \& Cropanzano, 1996), as previously mentioned, the experience of positive leadership triggers employee's positive emotions, which, in turn, leads to the perception of organizational identification. In other words, positive leadership, as a work environment, can serve as a contextual factor inducing employees' positive emotions and attitudinal responses (Ashkanasy \& Daus, 2002; Weiss \& Cropanzano, 1996). Specifically, employees who experience positive leadership at work are likely to perceive higher organizational identification, recognizing that their organization has a positive organizational culture compared to other organizations (Dutton \& Dukerich, 1991). Second, it is predicted that compassion could mediate the relationship between positive leadership and organizational identification. Specifically, positive leadership creates positive relationships and communication among employees, such as compassion (i.e., the experiences of consideration, gratitude, care, and forgiveness by others in the organization). Therefore, based on the social identity theory, such employees are more likely to identify themselves with their organizations (Allen, 2001; Ashforth \& Mael, 1989).

H6: Positive emotion mediates the relationship between positive leadership and organizational identification.

H7: Compassion mediates the relationship between positive leadership and organizational identification.

\section{AIMS}

This current study aims at underlining the mechanisms thorough how positive leadership enhances employees' organizational identification in large- sized Korean companies. Specifically, this study seeks to examine the mediating roles of compassion and positive emotions at work as a missing linkage in the relationship between positive leadership and organizational identification. Given that not much empirical studies have been conducted on compassion at work (Ko \& Choi, 2019), this study seeks to shed light on the positive roles of compassion in the workplace.

\section{METHODS}

\subsection{Participants and procedures}

In this study, surveys were conducted with employees working at ten large corporations in South Korea. Among the fourteen companies the research team contacted, ten companies decided to voluntarily participate in this study. Upon their approval, the research team visited the ten companies and gave a short presentation encouraging employees' voluntary participation. A total of 330 employees responded to the online surveys; excluding 18 surveys with insincere responses or central tendency, 312 surveys were used for data analysis. The majority of the participants were in their thirties $(N=130 ; 41.7 \%)$. Among the participants, 130 (41.7\%) were male. Many of the participants had worked for their current organizations for 1 to 4 years $(N=144 ; 46.2 \%)$, followed by those who had worked for their organizations for between 5 and 9 years $(N=68 ; 21.8 \%)$.

\subsection{Measurement}

\subsubsection{Positive leadership}

Based on the previous literature, positive leadership was defined as "[the] leadership that facilitates positive emotion and positive organizational culture while interacting with the team leader or all members of the organization" (Cameron \& Plew, 2012). Specifically, 14 items of the Positive Leadership Questionnaire (PLQ) by Cameron (2012) were used. Examples of the items include, "Our team leader allows team members to share personal information about each other so that they can know and care about each other's difficulties" and "The team leader encourages members to have positive energy." Positive leadership 
was measured on a 5-point Likert scale, indicating a Cronbach's a reliability coefficient of .963 .

\subsubsection{Positive emotion}

Positive emotion was defined as "the joyful, proud, and inspiring emotions experienced by organizational members" (Lilius et al., 2008). Specifically, four items by Lilius et al. (2008) were used. Sample items include "I am proud of everything" and "I am happy about everything." The items were measured on a 5-point Likert scale, and the scale's reliability was acceptable (Cronbach's alpha $=0.725)$.

\subsubsection{Organizational identification}

Organizational identification was defined as "to identify with the organization through the formation of organizational identity and to recognize the organization and its members as a common fate by sharing the goals of the organization to which they belong" (Mael \& Ashforth, 1992). Six items from Mael and Ashforth (1992) were used on a 5-point Likert scale. Examples of the items include: "I use the words 'our company' when talking about my company," and "I feel as if I'm being personally insulted if someone from outside criticizes my company". Cronbach's alpha reliability coefficient of the six items was .878 .

\subsubsection{Compassion}

Compassion was defined as "an act of responding to the suffering of others" (Lilius et al., 2011). Three items developed by Lilius and his colleagues (2008) were used. Sample items are "I often experience compassion at my workplace," "I often experience compassion from my supervisor," and "I often experience compassion from my colleagues." The items were measured on a 5-point Likert scale, and the scale's reliability was acceptable at a Cronbach's alpha value of 0.894 .

\subsubsection{Control variables}

Demographic variables (gender, age, position, the term of service, term of continuous service), which might affect the constructs of positive leadership, positive emotion, compassion, and organizational identification, were controlled. Furthermore, other compounding effects that individuals' propen- sity might have on the current study constructs were also controlled.

\section{RESULTS}

\subsection{Common method bias}

A cross-sectional study that simultaneously measures independent and dependent variables with self-reported responses may be biased (Podsakoff et al., 2003). Thus, Harman's one-factor test was conducted (Podsakoff \& Organ, 1986) to determine if the measurement of this study suffered common method bias issues. The results confirmed the presence of four distinct factors with an eigenvalue greater than 1.0, rather than a single factor, and the covariance explained by one factor was $17 \%$, indicating that the common method bias is not a serious concern (Podsakoff \& Organ, 1986; Podsakoff et al., 2003).

\subsection{Results of confirmatory factor analysis}

The discriminant validity was verified by Average Variance Extracted (AVE), and the internal reliability was examined with Cronbach's alpha coefficients. Cronbach's alpha coefficients of all the study variables were greater than 0.7 , and AVE values were greater than 0.6 for all latent variables, meeting the traditionally recommended criteria. The $\chi^{2}$ estimate was significant $\left(\chi^{2}(314)=583.257\right.$; $p<.001)$. The confirmatory factor analysis results are presented in Table 1.

Table 1. Confirmatory factor analysis results

\begin{tabular}{l|c|c|c|c|c|c}
\hline & CFI & TLI & RFI & NFI & RMSEA & RMR \\
\hline CFA & .960 & .955 & .907 & .917 & .053 & .031 \\
\hline
\end{tabular}

\subsection{Correlation analysis and validity test}

Multicollinearity was checked before testing the hypotheses. Pearson's coefficients were used to examine the correlations between latent variables. Regression analysis was conducted to check for multicollinearity, and the results showed that the variance inflation factors (VIFs) were between 1.127 and 1.262 , indicating no serious multicollin- 
Table 2. Correlation analysis results

\begin{tabular}{|c|c|c|c|c|}
\hline Variables & 1 & 2 & 3 & 4 \\
\hline$P L$ & .843 & & & \\
\hline Com & $.481^{* *}$ & .839 & & \\
\hline PA & $.575^{* *}$ & $.356^{* *}$ & .851 & \\
\hline $\mathrm{Ol}$ & $.488^{* *}$ & $.376^{* *}$ & $.536^{* *}$ & .878 \\
\hline Mean & 3.033 & 3.433 & 3.229 & 3.340 \\
\hline SD & .789 & .706 & .707 & .688 \\
\hline
\end{tabular}

Note: ${ }^{*} p<.05,{ }^{* *} p<.01,{ }^{* * *} p<.001$. The number in the diagonal is the square root of the AVE, PL = Positive Leadership, Com = Compassion, $\mathrm{PA}=$ Positive Affect, $\mathrm{OI}=$ Organizational Identification .

earity issues. Table 2 shows the correlation analysis results.

\subsection{Hypotheses testing}

After the confirmatory factor analysis, items with a low factor loading were removed from the model, resulting in three items for the construct of compassion, three items for compassion, four items for positive emotion, and five items for organizational identification. The hypothesis test was based on this final set of measurement items.

The fit of the research model was verified through a confirmatory factor analysis. The confirmatory factor analysis results for the measurement model are presented in Table 1, and the results of hypothesis testing are presented in Table 3. First, positive leadership experienced by employees turned out to be positively and significantly associated with positive emotion $(\beta=.605, p<.001)$, confirming H1. Positive leadership was positively and significantly associated with compassion $(\beta=.415, p<$ $.001)$, so H2 was supported. Third, positive emotion was positively and significantly associated with organizational identification $(\beta=.830, p<$ .001 ), supporting H3. Fourth, compassion was positively and significantly associated with organizational identification $(\beta=.477, p<.001)$, confirm- ing H4. Finally, organizational members' positive leadership turned out to be positively and significantly associated with organizational identification $(\beta=.605, p<.001)$, confirming H5.

Although regression has been commonly used to test the mediation effect, it failed to adequately reflect measurement errors and have been known to have limitations in examining complex and sophisticated mediation models such as a multi-mediation model or a double-mediation model (Luthans \& Youssef, 2007; Preacher \& Hayes, 2008). Thus, to overcome the limitations mentioned above in the conventional approach for testing mediation effects used bootstrapping by using the PROCESS. Bootstrapping helps determine whether indirect effects are statistically significant (CI 95\% = LLCI value, ULCI value). The bootstrapping results are presented in Tables 4 and 5. Using bootstrapping, the indirect effect of positive leadership on organizational identification through positive emotion was between LL95CI $=.118$ and UL95CI $=.283$. As zero (0) is not included in 95\% CI [.118, .283], the mediation effect was confirmed, supporting $H 6$. Besides, the indirect effect of positive leadership on organizational identification via compassion was between LL95CI $=.024$ and UL95CI $=.140$. As zero (0) is not included in 95\% CI [0.024, 0.140], $H 7$ was supported.

Table 3. Path analysis results

\begin{tabular}{|c|c|c|c|c|c|c|}
\hline $\mathbf{H}$ & Path & b & SE & CR & $\mathbf{P}$ & Test \\
\hline $\mathrm{H} 1$ & $\mathrm{PL} \rightarrow \mathrm{PE}$ & .605 & .051 & 11.815 & $<.001$ & Accept \\
\hline $\mathrm{H} 2$ & $\mathrm{PL} \rightarrow \mathrm{Com}$ & .415 & .052 & 7.964 & $<.001$ & Accept \\
\hline $\mathrm{H} 3$ & $\mathrm{PE} \rightarrow \mathrm{Ol}$ & .830 & .110 & 7.554 & $<.001$ & Accept \\
\hline $\mathrm{H} 4$ & $\mathrm{Com} \rightarrow \mathrm{OI}$ & .516 & .192 & 6.038 & $<.001$ & Accept \\
\hline $\mathrm{H} 5$ & $\mathrm{PL} \rightarrow \mathrm{OI}$ & .477 & .057 & 8.363 & $<.001$ & Accept \\
\hline
\end{tabular}

Note: $\mathrm{PL}=$ Positive Leadership, Com = Compassion, $\mathrm{PE}=$ Positive Emotion, $\mathrm{OI}=$ Organizational Identification. 
Table 4. Mediating effect of positive affect in the relationship between positive leadership and organizational identification

\begin{tabular}{l|c:c|c|c}
\hline \multicolumn{4}{c}{ Direct effect of $\mathbf{X}(\mathrm{PL})$ on $\mathbf{Y}(\mathrm{OI})$} \\
\hline & Effect & SE & $\mathbf{t}$ & $\mathbf{p}$ \\
\cline { 2 - 5 } & .234 & .049 & 4.741 & .000 \\
\hline & Indirect effect of X (PL) on Y (OI) \\
\hline Mediator & Effect & Boot SE & BootLLCI & BootULCI \\
\hline PE & .191 & .042 & .118 & .283 \\
\hline
\end{tabular}

Note: $\mathrm{PL}=$ Positive Leadership, $\mathrm{PE}=$ Positive Emotion, $\mathrm{OI}=$ Organizational Identification .

Table 5. Mediating effect of compassion in the relationship between positive leadership and organizational identification

\begin{tabular}{l|c|c|c|c}
\hline \multicolumn{5}{c}{ Direct effect of X (PL) on Y (OI) } \\
\hline \multirow{4}{*}{ Indirect effect of X (PL) on Y (OI) } \\
\cline { 2 - 5 } & Effect & SE & $\mathbf{t}$ & $\mathbf{p}$ \\
\hline Mediator & Effect & Boot SE & BootLLCl & BootULCI \\
\hline Com & .072 & .029 & .024 & .140 \\
\hline
\end{tabular}

Note: $\mathrm{PL}=$ Positive Leadership, Com = Compassion, $\mathrm{OI}=$ Organizational Identification.

\section{DISCUSSION}

\subsection{Implications}

The results of this current study provide several important implications. First, in contrast to the study by Lilius et al. (2008), which demonstrates the causal relationship between compassion, positive emotion, and affective commitment, this study demonstrates the mediating relationship between positive leadership and organizational identification through the formation of positive emotion and the experiences of compassion at work. Thus, the results add knowledge on the mechanisms through how positive leadership could lead to positive outcomes, such as organizational identification.

Second, this study emphasizes the benefits of virtuous behaviors such as gratitude, forgiveness, and positive emotion through positive leadership for employees struggling with excessive work burden, job stress, emotional exhaustion, and turnover intention. Because it is inevitable for employees to experience suffering at work, leaders' positive leadership behaviors could be integral to help employees form organizational identification, which, in turn, would lead to higher performance.

Third, this study emphasizes the development of relationships among the members of a particular company to high-quality connections when such members experience positive leadership, compassion as care, and compassionate acts (Dutton \& Heaphy, 2003). The results emphasize the roles of positive leadership in facilitating the formation of positive relationships among employees.

Fourth, this study demonstrates that positive leadership significantly influences organizational identification, unlike an empirical study on positive leadership regarding positive psychology or the Positive Organizational Scholarship (POS). Therefore, this current study provides a practical implication that when employees experience positive leadership, they develop compassion as an act of positive emotion and care. Ultimately, this reduces the turnover of excellent employees and facilitates the members' identification with the organization.

\subsection{Limitations and future research directions}

First, this study collected samples from employees in the metropolitan area, which limits generalization. In future studies, samples from various companies in the nation should be collected, including samples from Korea's non-metropolitan areas.

Second, this study used three items from the compassion scale based on the research by Lilius et al. (2008) who have conducted qualitative and quantitative research centered on the positive organizational scholarship since the late 1990s. However, in future studies, it is necessary to derive variables related to compassion, that is, core categories, through a qualitative research based on grounded theory in terms of the validity of the scale (Strauss \& Corbin, 1997). Therefore, in future studies, it is necessary to derive a research model for empirical study based on the causal relationships of these core categories to further prove the validity of the compassion scale. 
Third, this study demonstrated the causal relationship between organizational identification and positive leadership as the dependent variable. However, in the future, studies should be conducted to demonstrate the causal relationship between positive leadership and job enthusiasm, positive leadership and incivility, and positive leadership and other performance variables.

Fourth, this study shows the limitation of conducting a cross-sectional study, and the problem of the directionality of the causal relationship can be raised as the samples were collected at some time. For example, the hypothesis implies a causal assumption that members of an organization who have experienced positive leadership will positively affect compassion. However, in the actual results, it is impossible to exclude the possibility that compassion, the outcome variable of this current study, affects positive leadership. Therefore, in future research, it is necessary to collect samples through longitudinal studies to make up for the limitations of such a cross-sectional analysis.

\section{CONCLUSION}

This current study provided empirical evidence supporting the mediating effects of compassion and positive emotion in the relationships between positive leadership and organizational identification, given the increasing importance of positive leadership in organizations, especially in the realms of positive organizational scholarship. This current study expands the understanding of the mechanisms through how positive leadership enhances followers' organizational identification. Future research employing a longitudinal research design and samples in different cultures could further validate and strengthen the results. It is integral for organizations to recognize the importance of positive leadership in practice. Especially, given that organizational identification is critical for organizational performance and talent management, organizations should provide leaders with adequate leadership training so that they can develop their positive leadership skills.

\section{AUTHOR CONTRIBUTIONS}

Conceptualization: Sung-Hoon Ko.

Data curation: Sung-Hoon Ko.

Formal analysis: Sung-Hoon Ko.

Investigation: Sung-Hoon Ko, Yongjun Choi.

Methodology: Sung-Hoon Ko, Yongjun Choi.

Project administration: Sung-Hoon Ko.

Validation: Sung-Hoon Ko, Yongjun Choi.

Visualization: Yongjun Choi.

Writing - original draft: Sung-Hoon Ko.

Writing - review \& editing: Sung-Hoon Ko, Yongjun Choi.

\section{REFERENCES}

1. Allen, T. D. (2001). Familysupportive work environments: The role of organizational perceptions. Journal of Vocational Behavior, 58(3), 414-435. https:// doi.org/10.1006/jvbe.2000.1774

2. Ashforth, B. E., \& Mael, F. (1989). Social identity theory and the organization. Academy of Management Review, 14(1), 20-39. https://doi.org/10.5465/ amr.1989.4278999
3. Ashkanasy, N. M., \& Daus, C. S. (2002). Emotion in the workplace: The new challenge for managers. The Academy of Management Executive, 16(1), 76-86. https://doi. org/10.5465/ame.2002.6640191

4. Bartel, C. A. (2001). Social comparisons in boundaryspanning work: Effects of community outreach on members' organizational identity and identification. Administrative
Science Quarterly, 46(3), 379-413. https://doi.org/10.2307/3094869

5. Blau, P. M. (1964). Justice in social exchange. Sociological Inquiry, 34(2), 193-206. https://doi. org/10.1111/j.1475-682X.1964. tb00583.x

6. Brief, A. P., \& Roberson, L. (1989). Job attitude organization: An exploratory study. Journal of Applied Social Psychology, 
19(9), 717-727. https://doi. org/10.1111/j.1559-1816.1989. tb01254.x

7. Cameron, K. (2012). Positive leadership: Strategies for extraordinary performance. San Francisco, CA: Berrett-Koehler Publishers.

8. Cameron, K. S. (2008). Paradox in positive organizational change. Journal of Applied Behavioral Science, 44(1), 7-24. https://doi. org/10.1177/0021886308314703

9. Cameron, K. S., \& Plews, E. (2012). Positive leadership in action: Applications of POS by Jim Mallozzi, CEO, Prudential Real Estate and Relocation. Organizational Dynamics, 41(2), 99-105. Retrieved from https:// langleygroupinstitute.com/ wp-content/uploads/CameronPlews-2012-Positive-leadershipin-action-copy.pdf

10. Cialdini, R. B., Borden, R. J., Thorne, A., Walker, M. R., Freeman, S., \& Sloan, L. R. (1976). Basking in reflected glory: Three (football) field studies. Journal of Personality and Social Psychology, 34(3), 366-375. https://doi. org/10.1037/0022-3514.34.3.366

11. D’Innocenzo, L., Mathieu, J. E., \& Kukenberger, M. R. (2016). A meta-analysis of different forms of shared leadership team performance relations. Journal of Management, 42(7), 1964-1991. https://doi.org/ 10.1177\%2F0149206314525205

12. Damen, F., Van Knippenberg, B., \& Van Knippenberg, D. (2008). Affective match in leadership: Leader emotional displays, follower positive affect, and follower performance. Journal of Applied Social Psychology, 38(4), 868-902. Retrieved from http://files.la-grinta.webnode. nl/200000006-ac3d7ad36a/Affective\%20Match_JASP.pdf

13. Dutton, J. E., \& Dukerich, J. M. (1991). Keeping an eye on the mirror: Image and identity in organizational adaptation. Academy of Management Journal, 34(3), 517-554. https://doi. org/10.5465/256405
14. Dutton, J. E., \& Heaphy, E. D. (2003). The power of high-quality connections. In K. Cameron \& J. Dutton (Eds.), Positive organizational scholarship: Foundations of a new discipline (pp. 263-278). Berrett-Koehler Publishers.

15. Dutton, J. E., Dukerich, J. M., \& Harquail, C. V. (1994). Organizational images and member identification. Administrative Science Quarterly, 39(2), 239-263. https://doi. org/10.2307/2393235

16. Eisenberger, R., Cummings, J., Armeli, S., \& Lynnch, P. (1997). Perceived organizational support, discretionary treatment, and job satisfaction. Journal of Applied Psychology, 82(5), 812-820. https://doi.org/10.1037/00219010.82.5.812

17. Fisher, C. D. (2000). Mood and emotions while working: Missing pieces of job satisfaction. Journal of Organizational Behavior, 21(2), 185-202. https:// doi.org/10.1002/(SICI)10991379(200003)21:2<185::AID JOB34>3.0.CO;2-M

18. Fredrickson, B. L. (2001). The role of positive emotions in positive psychology: The broaden-andbuild theory of positive emotions. American Psychologist, 56(3), 218226. https://doi.org/10.1037/0003066X.56.3.218

19. Hannah, S. T., Woolfolk, R. L., \& Lord, R. G. (2009). Leader self-structure: a framework for positive leadership. Journal of Organizational Behavior, 30(2), 269-290. https://doi.org/10.1002/ job. 586

20. Hoch, J. E., Bommer, W. H., Dulebohn, J. H., \& Wu, D. (2018). Do ethical, authentic, and servant leadership explain variance above and beyond transformational leadership? A meta-analysis. Journal of Management, 44(2), 501-529. https://doi. org/10.1177/0149206316665461

21. Hur, W. M., Moon, T. W., \& Ko, S. H. (2018). How employees' perceptions of CSR increase employee creativity: Mediating mechanisms of compassion at work and intrinsic motivation. Journal of Business Ethics, 153(3), 629-644. https://doi.org/10.1007/ s10551-016-3321-5

22. Kahn, W. A. (1993). Caring for the caregivers: Patterns of organizational caregiving. Administrative Science Quarterly, 38(4), 539-563. Retrieved from https://eric.ed.gov/?id=EJ477552

23. Kelloway, E. K., Wiegand, H., McKee, M. C., \& Das, H. (2013). Positive leadership and employee well-being. Journal of Leadership \& Organizational Studies, 20(1), 107-117. https://doi. org/10.1177/1548051812465892

24. Kirkpatick, S. A., \& Locke, E. A. (1991). Leadership: Do traits matter? Academy of Management Perspectives, 5(2), 48-60. https://doi.org/10.5465/ ame.1991.4274679

25. Ko, S. H., \& Choi, Y. (2019). Compassion and job performance: Dual-paths through positive workrelated identity, collective self esteem, and positive psychological capital. Sustainability, 11(23), 6766. https://doi.org/10.3390/ su11236766

26. Liden, R. C., Erdogan, B., Wayne, S. J., \& Sparrowe, R. T. (2006). Leader-member exchange, differentiation, and task interdependence: Implications for individual and group performance. Journal of Organizational Behavior, 27(6), 723. https://doi.org/10.1002/ job.409

27. Lilius, J. M., Worline, M. C., Dutton, J. E., Kanov, J. M., \& Maitlis, S. (2011). Understanding compassion capability. Human Relations, 64(7), 873-899. https://doi. org/10.1177/0018726710396250

28. Lilius, J. M., Worline, M. C., Maitlis, S., Kanov, J., Dutton, J. E., \& Frost, P. (2008). The contours and consequences of compassion at work. Journal of Organizational Behavior, 29(2), 193-218. https:// doi.org/10.1002/job.508

29. Linley, P., Govindji, R., \& West, M. (2007). Positive 
psychology approaches to public services leadership: An introduction to strengthsbased leadership. International Journal of Leadership in Public Services, 3(4), 44-55. https://doi. org/10.1108/17479886200700029

30. Mael, F., \& Ashforth, B. E. (1992). Alumni and their alma mater: A partial test of the reformulated model of organizational identification. Journal of Organizational Behavior, 13(2), 103-123. https://doi.org/10.1002/ job.4030130202

31. Meyer, J. P., \& Allen, N. J. (1991). A three-component conceptualization of organizational commitment. Human Resource Management Review, 1(1), 61-89. https://doi.org/10.1016/10534822(91)90011-Z

32. Miller, K. I. (2007). Compassionate communication in the workplace: Exploring processes of noticing, connecting, and responding. Journal of Applied Communication Research, 35(3), 223-245. https://doi. org/10.1080/00909880701434208

33. Montano, D., Reeske, A., Franke, F., \& Hüffmeier, J. (2017). Leadership, followers' mental health and job performance in organizations: A comprehensive meta-analysis from an occupational health perspective. Journal of Organizational Behavior, 38(3), 327-350. https://doi. org/10.1002/job.2124

34. Moon, T. W., Hur, W. M., Ko, S. H., Kim, J. W., \& Yoon, S. W. (2014). Bridging corporate social responsibility and compassion at work: Relations to organizational justice and affective organizational commitment. Career Development International, 19(1), 49-72. https:// doi.org/10.1108/CDI-05-20130060

35. Podsakoff, P. M., \& Organ, D. W. (1986). Self reports in organizational research: Problems and prospects. Journal of Management, 12(4), 531-544. https://doi. org/10.1177/014920638601200408

36. Podsakoff, P. M., MacKenzie, S. B., Lee, J. Y., \& Podsakoff, N. P.
(2003). Common method biases in behavioral research: A critical review of the literature and recommended remedies. Journal of Applied Psychology, 88(5), 879903. https://doi.org/10.1037/00219010.88.5.879

37. Preacher, K. J., \& Hayes, A. F. (2008). Asymptotic and resampling strategies for assessing and comparing indirect effects in multiple mediator models. Behavior Research Methods, 40(3), 879-891. https://doi.org/10.3758/ BRM.40.3.879

38. Rego, A., Sousa, F., Marques, C., \& Cunha, M. P. (2014). Hope and positive affect mediating the authentic leadership and creativity relationship. Journal of Business Research, 67(2), 200210. https://doi.org/10.1016/j. jbusres.2012.10.003

39. Rhoades, L., Eisenberger, R., \& Armeli, S. (2001). Affective commitment to the organization: The contribution of perceived organizational support. Journal of Applied Psychology, 86(5), 825-836. https://doi.org/10.1037/00219010.86.5.825

40. Staw, B. M., \& Barsade, S. G. (1993). Affect and managerial performance: A test of the sadderbut wiser vs. happier-and-smarter hypotheses. Administrative Science Quarterly, 38(2), 304-331. https:// doi.org/10.2307/2393415

41. Strauss, A., \& Corbin, J. M. (1997). Grounded theory in practice. Thousand Oaks, CA: Sage.

42. Tajfel, H., \& Turner, J. C. (1986). The social identity theory of intergroup behavior. In S. Worchel \& W. Austin (Eds.), Psychology of intergroup relations (pp. 7-24). Chicago: Nelson-Hall.

43. Weiss, H. M., \& Cropanzano, R. (1996). Affective events theory: A theoretical discussion of the structure, causes, and consequences of affective experiences at work. In B. M. Staw \& L. L. Cummings (Eds.), Research in organizational behavior (Vol. 18, pp. 1-74). New York: Elsevier Science. Retrieved from http:// web.mit.edu/curhan/www/docs/ Articles/15341_Readings/Affect/
AffectiveEventsTheory_WeissCropanzano.pdf

44. Youssef, C. M., \& Luthans, F. (2012). Positive global leadership. Journal of World Business, 47(4), 539-547. Retrieved from https://core.ac.uk/download/ pdf/188103707.pdf

45. Youssef-Morgan, C. M., \& Luthans, F. (2013). Positive leadership: Meaning and application across cultures. Organizational Dynamics, 42(3), 198-208. https://doi.org/10.1016/j. orgdyn.2013.06.005 